\title{
Does the Croatian Stock Market Have Seasonal Affective Disorder?
}

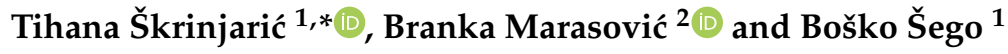 \\ 1 Department of Mathematics, Faculty of Economics and Business, University of Zagreb, 10000 Zagreb, Croatia; \\ bsego@net.efzg.hr \\ 2 Department of Quantitative Methods, Faculty of Economics, Business and Tourism, University of Split, \\ 21000 Split, Croatia; branka.marasovic@efst.hr \\ * Correspondence: tskrinjar@net.efzg.hr; Tel.: +385-12383325
}

Citation: Škrinjarić, Tihana, Branka Marasović, and Boško Šego. 2021. Does the Croatian Stock Market Have Seasonal Affective Disorder? Journal of Risk and Financial Management 14: 89. https://doi.org/10.3390/jrfm 14020089

Academic Editor: Andreia Dionísio

Received: 12 January 2021

Accepted: 18 February 2021

Published: 21 February 2021

Publisher's Note: MDPI stays neutral with regard to jurisdictional claims in published maps and institutional affiliations.

Copyright: (C) 2021 by the authors. Licensee MDPI, Basel, Switzerland. This article is an open access article distributed under the terms and conditions of the Creative Commons Attribution (CC BY) license (https:/ / creativecommons.org/licenses/by/ $4.0 /)$.

\begin{abstract}
This paper explores mood anomalies, specifically the seasonal affective disorder (SAD) effect on the Zagreb Stock Exchange (ZSE). SAD is defined as a syndrome of depressive episodes in human behavior due to the changing of the season. Thus, the motive of this research is to gain better insights into the investors' sentiment regarding SAD effects. The purpose of the research is to observe how investors' sentiment affects the return and risk series on ZSE and if this could be exploitable. Using daily data on stock market return CROBEX for the period January 2010February 2021, SAD effects are tested to explore if seasonal changes affect the stock returns and risk. Besides the SAD variable in the model, some control variables are included as well: Monday, tax, and COVID-19 effect. The results indicate that SAD effects exist on ZSE, even with controlling for mentioned effects; and asymmetries around winter solstice exist. Implications of such findings can be found in simulating trading strategies, which could incorporate such information to gain profits. Limitations of the research focus on one market, observing static parameters of the estimated models, and observing simple trading strategies. Thus, future research should focus on international diversification possibilities, time-varying models, and fully exploring the exploitation possibilities of such findings.
\end{abstract}

Keywords: seasonal affective disorder; stock market; seasonality; behavioral finance; market blues; COVID-19; anomalies

\section{Introduction}

Seasonal affective disorder (or winter blues, SAD henceforward) is a term developed in psychiatry in the late 1980s. It is defined as a mood disorder of humans who exhibit normal behavior and mood in the majority of the calendar year except fall and winter monthsrelated to changes in seasons (Rosenthal et al. 1984; Rosenthal 1998, 2012; Mayoclinic 2018). For a detailed list from a psychological point of view, please refer to Roecklein and Rohan (2005). This phenomenon and its effects on investors and financial markets have become a more interesting topic of research in the last 10 years. How does SAD affect stock market participants and stock market returns; what are the consequences to investors' trading strategies; as well as what are the implications to the financial theory and theoretical models are some of the interesting questions which arise in this field of research. From a theoretical point of view, the Efficient Market Hypothesis (EMH) of E. Fama $(1965,1970)$ has been criticized, questioned, and tested on stock markets ever since it was formalized (e.g., Yu et al. 2011; extensive list in Škrinjarić 2012). Nowadays, even the crypto currencies are evaluated in terms of EMH (Kyriazis 2019). The SAD effects are often connected to behavioral finance, especially since the seminal work of Kahneman, Tversky, Shiller, Vishny, etc. (see Shleifer 1999). The behavioral literature shows that peoples' mood has significant effects on the decision-making process and its outcomes (see Loewenstein et al. 2001 for risk-as-feeling hypothesis or especially; Johnson and Tversky 1983). Thus, if finding such 
anomalies on stock markets, the theoretical framework of rational finance models becomes questionable, due to the assumptions of preferences, decisions, and judgment of stock market participants.

Empirical psychological research has established a link between weather, wind, daylight hours, etc., and peoples' mood. Denissen et al. (2008) experiment observed that tiredness and depressive symptoms of peoples' feelings depend on sunlight and season of the year. Results of the experiment on 1233 participants showed that there exist so-called winter blues (or the seasonal affective disorder), where depressive feelings are correlated to the reduction of daylight. Moreover, from an empirical point of view, questions regarding profitable trading strategies arise if such effects exist on a stock market. These effects can affect returns and risk premiums of portfolios. Thus, SAD influences investor's goals and the whole investment process. The empirical research on SAD effects on stock markets is getting wider, especially in the last couple of years.

If we focus on the investor sentiment literature in general, with linkages to the SAD effects, there are some major conclusions. Laeven and Valencia (2008) examined 124 systemic financial crises since the 1970s and found that stock prices were mainly determined by investors' feelings (panic, greed, fear, enthusiasm). These feelings affect investment decisions in terms of under of over-reacting during specific periods (Škrinjarić et al. 2020), which has been more thoroughly examined since Baker and Wurgler (2006, 2007) quantified the variable of investors' sentiment. Some of the challenges of constructing such variables can be found in Banchit et al. (2020). Previous sentiment proxies can be found in Huang et al. (2014) and Concetto and Ravazzolo (2019). One of the early models which explain why sentiment distorts the stock prices is found in De Long et al. (1990), where the noise traders are those who introduce a systematic risk. Such types of traders are either over-reactors both to good and bad news, which either increases or decreases prices too high or too low, depending upon the sentiment (Lee et al. 2002). By focusing on investor mood specifically, two theories explain how this affects risk aversion. The affect infusion model of Forgas (1995): negative moods increase risk aversion, and the opposite is true for the positive mood. The mood maintenance hypothesis, on the other side, explains that a positive mood is an explanation of avoiding risks, to maintain such a mood (Isen et al. 1988; Isen and Patrick 1983). The opposite is true for moodier people. They are willing to take more risk due to expecting positive outcomes which will enhance their mood. Kramer and Weber (2011) think that the SAD effects are better explained within the affect infusion model.

However, the majority of the empirical SAD literature observes most developed stock markets. Moreover, literature which observes other financial assets has been emerging as well (such as mutual funds and treasury bonds, see Kamstra et al. 2008a, 2008b, 2009); and on different actions of stock market participants (such as IPO-s, see Dolvin and Pyles 2007). Few papers focus on markets in development, such as the Croatian market, as a small illiquid market. Some of the reasoning on why investors should be interested in the Croatian market is as follows. This market has a great market capitalization in terms of percentage of GDP (Šego and Škrinjarić 2018), which indicates that although the liquidity is a problem in such markets, some money is turned-over on some of them, including Croatia. Next, Baele et al. (2015) found that the Croatian market had a lower correlation with the (MSCI-Morgan Stanley Capital International) World market index, overall European market index, the emerging market index, and the Russian market index returns, alongside lower Hurdle rate for the international diversification possibilities, which makes it attractive for international investors. Furthermore, the uncertainties which affect investor sentiment were found to be significant for the Croatian market in Škrinjarić and Orlović (2020). Since these findings enable the investors to better forecast future return on this market, it could be exploitable, if the SAD effects were found on such market. These inefficiencies could be exploitable in line with Milošević Avdalović and Milenković (2017) and Radovanov and Marcikić (2017). 
The growing literature of applications on financial markets is not surprising, due to documented links between depression and risk-aversion attitudes of people and investors. Some of the papers include Kliger and Levy's (2008) research in the spirit of Kahneman and Tversky (1979) prospect theory. Different mood-changing triggers have been already observed in the literature, such as lunar cycle effects in Dowling and Lucey $(2005,2008)$; sunshine effects on investors' mood in Hirshleifer and Shumway (2003); and daylight savings effects in Pinegar (2002) or Muller et al. (2009), etc. Many of the mentioned empirical research has been published in respectable journals (such as Journal of Finance, Journal of Banking \& Finance, American Economic Review, etc.), which indicates the strong theoretical support in these types of studies. More reasoning on why we focus on these issues is as follows. A proper analysis of time-varying risk aversion and risk itself is needed. Emerging markets, such as the Croatian example, provide more possibilities to exploit possible inefficiencies. However, as stated, such markets are less investigated in the literature. If international investors, especially speculators, are better introduced to such markets and their characteristics, such markets will become more attractive. This still represents a problem, although some recent literature recognizes the attractiveness of risk-adjusted returns of such markets (Golab et al. 2015). Finally, the growing body of literature on sentiment affecting the financial markets cannot be ignored: Bathia and Bredin (2013) found that sentiment affects future return series; Rupande et al. (2019), Naik and Padhi (2016) found that sentiment affects the volatility series as well; gold as asset and effects on its return and risk are affected as well (Balcilar et al. 2018); government bond yields are found to be affected in Su et al. (2020), and oil returns in Du et al. (2016), etc. All these findings cannot simply be ignored as data snooping.

The types of studies related to this study in particular are very scarce in Croatia. The SAD effects in detail have not yet been explored in the Croatian stock market. Only one paper exists (Škrinjarić 2018) which broadly observed several CEE (Central and Eastern European) and SEE (South and Eastern Europe) markets at once, including the Croatian market. The mentioned research found SAD effects on ZSE, however, this study extends that research via different robustness checking of results and including the analysis of SAD effects on time-varying risk. The purpose of the paper is twofold. The first one is to familiarize readers with the topic and to give an overview of relevant literature. The second purpose is to empirically evaluate SAD effects on ZSE: if they exist, how do they affect returns and risk premium. Thus, the contributions of this paper are found in the following. Firstly, a more detailed analysis of the SAD effects on ZSE is conducted, by including several approaches of robustness testing. Next, simple trading strategies are formed based on the results to examine if any exploitable strategies could exist. The results of these simulations show that using knowledge from the obtained results could be helpful in achieving good portfolio values. Such analysis is ignored in the existing literature. Although empirical evidence is found in favor of SAD effects on stock or other markets, the question remains on how to exploit such information. The rest of the paper is structured as follows. Section 2 gives an overview of previous relevant and related research. Section 3 describes the used methodology in the Section 4, empirical part of the research. The final, Section 5 concludes the paper.

\section{Previous Research}

This section reviews previous existing research on the SAD topic to get useful insights. Several main conclusions can be made based on the literature review. Firstly, although research is growing, it is still mostly concentrated on more developed stock markets. This area of study does not have yet the overwhelming amount of empirical research such as other areas of empirical finance (e.g., calendar anomalies, asset pricing models, etc.). The majority of existing research is focused on the more developed markets. Finally, to the knowledge of the authors, there exists only one paper regarding Croatia and the topic of this paper, in which the author observes an ARMA-GARCH (autoregressive moving average-generalized autoregressive conditional heteroskedasticity) specification of the 
model for ZSE, as well as for other CEE and SEE markets. The research examined in the

Table 1.

rest of this section is summarized in

Table 1. Summarization of previous findings.

\begin{tabular}{|c|c|c|}
\hline Authors (year) & Market, Data & Findings \\
\hline Kamstra et al. (2003) & $\begin{array}{c}\text { US, Sweden, UK, Germany, Canada, New } \\
\text { Zealand, Japan, Australia, South Africa; } \\
\text { 1928-2003 }\end{array}$ & $\begin{array}{l}\text { Seasonal affective disorder (SAD) effects } \\
\text { exist, greater effects when further from } \\
\text { the equator }\end{array}$ \\
\hline Garrett et al. (2005) & $\begin{array}{l}\text { US, UK, Japan, Sweden, New Zealand, and } \\
\text { Australia; 1962-2000 }\end{array}$ & SAD effects exist \\
\hline Jacobsen and Marquering (2008) & 48 countries; $1970-2004$ & SAD effects insignificant \\
\hline Kamstra et al. (2009) & Replication of Jacobsen and Marquering (2008) & $\begin{array}{l}\text { SAD effects found, problems of } 2008 \\
\text { paper found }\end{array}$ \\
\hline Dolvin et al. (2009) & US, 1998-2004 & Analysts' forecasts are under SAD effects \\
\hline Stefanescu and Dumitriu (2011) & Romania, 2002-2011 & $\begin{array}{l}\text { SAD effects found, but no control } \\
\text { variables included }\end{array}$ \\
\hline Hammami and Abaoub (2011) & Tunis, 1998-2008 & $\begin{array}{l}\text { No SAD effects, Tunis is close to the } \\
\text { equator }\end{array}$ \\
\hline Lo and Wu (2018) & US, 1998-2004 & $\begin{array}{l}\text { Pessimistic analyst forecasts when SAD } \\
\text { effects hold }\end{array}$ \\
\hline Murgea (2016) & Romania, 2000-2014 & $\begin{array}{l}\text { SAD effects found in every subsample } \\
\text { (before, during and after } 2008 \text { crisis) }\end{array}$ \\
\hline Škrinjarić (2018) & $\begin{array}{c}\text { Bosnia and Herzegovina, Bulgaria, Croatia, } \\
\text { Czech Republic, Hungary, Poland, Serbia, } \\
\text { Slovakia, Slovenia, Romania, and Ukraine, } \\
\text { 2010-2018 }\end{array}$ & $\begin{array}{l}6 \text { out of } 11 \text { (Croatia included) had SAD } \\
\text { effects, only return series observed }\end{array}$ \\
\hline
\end{tabular}

The weather and climate effects on investors' feelings and stock markets have been observed for 25 years now (see Saunders 1993; Hirshleifer and Shumway 2003; or Cao and Wei 2005). The first paper which introduced the SAD effects on stock returns was Kamstra et al. 2003). Although there were some studies already existing on how the weather affects the mood of investors (see Kamstra et al. 2003; and Xu 2016 for references), the Kamstra et al. $(2002,2003)$ papers formally introduced the SAD measure based on normalized hours of the night. Authors observed the US, Swedish, UK, German, Canadian, New Zealand, Japanese, Australian, and South African markets for different periods (daily data ranging from 1928 for some markets up to 1991 to others, depending upon the availability of data). The results indicated the presence of SAD effects on observed markets, especially when the latitude of the market is more distant from the equator. This is because the changes of day and night and their length over the year vary more the further we move from the equator. Control variables were included to avoid spurious results (e.g., autocorrelation). Authors simulated trading strategies based on the results. The conclusion was that there exist potential profits if following those strategies. Garrett et al. (2005) extended this research to the Capital Asset Pricing Model (CAPM) model and observed SAD effects in the asset pricing setting using daily and monthly data (period start date changes depending upon the availability of data: 1962-2000) for the US, UK, Japan, Sweden, New Zealand, and Australia. The existing model was extended to a conditional CAPM type and results of estimations indicated that the price of risk varies depending upon the seasonal variation of the SAD effect. These results are consistent with previous literature's findings of being more risk-averse during SAD months.

Jacobsen and Marquering (2008) challenge the SAD effect with the Halloween indicator inclusion in the analysis. The basic idea is that the Halloween indicator captures the calendar effects in stock returns which differ from the May to Halloween period compared 
to the rest of the year. Authors considered 48 countries in the analysis (ranging from Europe to Asia and South America; Croatia not included) in different periods (depending on the (un)availability of data for each country, 1970-2004, monthly data). The authors conclude that variation of returns could not be affected by season changes and moods due to the inclusion of calendar effect which captures those variations whilst SAD effects become insignificant. Moreover, the authors speculate about the possibility that the SAD effect is rather a data-driven inference. This research was questioned and challenged in the following year, in Kamstra et al. (2009). Latter authors tried to replicate results from Jacobsen and Marquering (2008), but with no success. They got different results for the same countries; found that paper from 2008 miss-specifies the model utilized in the study, as well as it observed countries which were too close to the equator which means that little variation of daylight and night hours interchange. Finally, the SAD effect in the 2009 study was found to be significant despite the Halloween effects.

Dolvin et al. (2009) focused on the effects of SAD on financial analysts' forecasts and errors for the period 1998-2004 in the USA. Authors observed forecasts and actual values of EPS (earnings per share) and control variables (for high tech firms, institutional ownership, etc.). The results indicated that overall, analysts are optimistic. However, optimism is lower in SAD months, which contributes to more accurate forecasts. Thus, it could be claimed that rational models in finance that do not take into account human behavior, feelings, and mood could result in estimation bias and less accurate results and forecasts. A related study is Lo and Wu (2018), in which authors extend the research from 2009 with the same data. The newer research has several findings: financial analysts are more pessimistic in fall, which contributes to lower precision of forecast, a robust result in the whole sample. Moreover, this pessimism is due to SAD effects, which reverses in spring.

Stefanescu and Dumitriu (2011) focused on the Romanian market, in the period Jan 2002-Sep 2011. Authors observe daily data and divide the time sample into two subsamples, depending upon the financial crisis (the first sub-period was until September 12th, 2008). Authors observe a basic model, with the LS approach of estimation. The SAD effects were found to be significant in both subsamples, with greater effects during the financial crisis period. However, the authors state that no control variables were included in the analysis. Hammami and Abaoub (2011) explored the Tunisian market (Jan 1998-Dec 2008) to test for SAD effects. This research did not find evidence in favor of the SAD effect, which authors try to explain with Tunis being close to the equator line. In that way, the variation of day and night hours is less prominent and does not affect that much investor's moods. However, authors only observe the basic form of the model with only SAD effects included, so results should be taken with caution. Another study of the Romanian market was conducted in 2016. Murgea (2016) observed the Romanian market in the period 2000-2014. Since the financial crisis was included in the sample, the author divided the sample into three sub-periods to capture the effects of the crisis and see if SAD effects have changed before and after the crisis. The first sub-period was the rapid growth period (until Jun 2007), the second is the crisis (until Oct 2012) and the last one was called the recovery period. The author found SAD effects on stock returns in Romania before and after the crisis; the effects are weak in the crisis period, even when controlling for the January effects. Škrinjarić (2018) focused on 11 markets in total (Bosnia and Herzegovina, Bulgaria, Croatia, Czech Republic, Hungary, Poland, Serbia, Slovakia, Slovenia, Romania, and Ukraine) for the period 2010-2018. The author utilized ARMA-GARCH specifications for the mentioned markets and found that 6 out of 11 markets exhibit SAD effects, including Croatia. Thus, the conclusion was that future theoretical and empirical work should include the time-varying risk aversion in the analysis.

It can be seen that majority of results support the existence of SAD effects on stock markets, which leads to the questionability of rational asset pricing models and profitable trading strategies on stock markets. Since detailed analysis as in this research was not utilized for the Croatian market, the next sections focus on the Croatian market to fill that gap in the literature. 


\section{Methodology Description}

A brief overview of the methodology used in this type of studies follows (as in Kamstra et al. 2003). Define with $H_{t}$ hours from sunset to sunrise at any location at date $t$. The SAD measure at time $t$ is defined via photoperiod as:

$$
S A D_{t}= \begin{cases}H_{t}-12, & t \text { in fall and winter } \\ 0, & \text { otherwise }\end{cases}
$$

where $12 \mathrm{~h}$ represents the average number of hours of night at an location over the entire year. Notice that $S A D_{t}$ measure is observed only during the fall and winter time, as previous medical literature determined that it affects people during that time only (see Jacobsen and Marquering 2008). $H_{t}$ is defined from spherical trigonometry as:

$$
H_{t}= \begin{cases}24-7.72 \operatorname{arcos}\left(-\tan \left(\frac{2 \pi \delta}{360}\right) \tan \lambda_{t}\right), & \text { Northern hemisphere } \\ 7.72 \operatorname{arcos}\left(-\tan \left(\frac{2 \pi \delta}{360}\right) \tan \lambda_{t}\right), & \text { Southern hemisphere }\end{cases}
$$

where $\lambda_{t}$ is sun's declination angle at latitude $\delta, \lambda_{t}=0.4102 \sin \left(\frac{2 \pi}{365}\left(J_{t}-80.25\right)\right)$ and $J_{t}$ variable which ranges from 1 to 365 (or 366), depending upon the day of the year. The asymmetry in risk aversion around winter solstice is regarded in the literature as well. Kamstra et al. (2003) defined it as the following variable:

$$
F_{t}= \begin{cases}S A D_{t}, & \text { for } t \text { in fall } \\ 0, & \text { otherwise }\end{cases}
$$

It basically captures the asymmetric effects of increase of risk aversion in fall towards winter, which in turn should be resulted with lower returns compared to those when the winter solstice passes. The basic model to test SAD effects on the stock returns is:

$$
r_{t}=\mu+\sum_{i=1}^{p} \rho_{i} r_{t-i}+\beta_{S A D} S A D_{t}+\beta_{M} M_{O N}+\beta_{\text {Tax }} \operatorname{Tax}_{t}+\beta_{\mathrm{cov}} \operatorname{Cov}_{t}+\varepsilon_{t}
$$

$$
\text { (Model 1) }
$$

where $r_{t}$ denotes return at time $t$, lagged values of return series are added to control autocorrelation, $M O N_{t}$ is the first control variable, capturing effects of Monday (value is equal to 1 on Mondays, 0 otherwise); and the second control variable is Tax $x_{t}$ is tax-loss selling binary variable (equal to 1 for the last day of the tax year and first four of the next, 0 othervise). The error term is denoted with $\varepsilon_{t}$. The MON effects (Monday or weekend effects) are one of the most famous calendar anomalies in the literature, explained in e.g., Miller (1988), where the author states that investors gain new information on stocks over the weekend. On Mondays, investors usually try to restructure their portfolios due to new information obtained over the weekend. This makes price pressures by lowering prices on Mondays. The tax selling anomaly is explained in, e.g., Lakonishok and Smidt (1988) or Agrawal and Tandon (1994). Basically, investors sell parts of their portfolios at the end of the year in order to pay fewer taxes on capital gains due to having lower performing stocks in the portfolios. At the beginning of a new year, the investors buy back the stocks they sold at the end of the previous year. For more details on mentioned calendar anomalies please refer to Škrinjarić (2012). Finally, as previous newer research finds the effects of COVID-19 pandemics on return and volatility series (Zhang et al. 2020; Barro et al. 2020; He et al. 2020), we include the binary variable Covt which is equal to 1 starting from 1 February 2020 to 28 April 2020. 
In order to test for asymmetry effects, variable $F_{t}$ is added in model (4):

$$
r_{t}=\mu+\sum_{i=1}^{p} \rho_{i} r_{t-i}+\beta_{S A D} S A D_{t}+\beta_{M} M N_{t}+\beta_{\text {Tax }} \operatorname{Tax}_{t}+\beta_{F} F_{t}+\beta_{\mathrm{cov}} \operatorname{Cov}_{t}+\varepsilon_{t}
$$

(Model 2)

Models (4) and (5) were estimated via least squares estimation method and robust standard errors. If SAD effects are present in stock returns, $\beta_{S A D}$ should be positive and if asymmetry exists in investors' risk aversion, value of $\beta_{F}$ should be negative. This means that more depressed and risk averse investors stay away from riskier asset in fall and winter by selling stocks and buying safer assets when days are getting shorter. However, the asymmetric effects when comparing fall and winter days should be captured in the negative value of $\beta_{F}$, which describes changing patterns of selling more stocks as winter is coming and buying them again as winter solstice passes.

In order to test SAD effects on the market risk in context of CAPM methodology, Merton (1973) conditional CAPM can be observed (here we followed the Garrett et al. 2005 approach):

$$
E_{t-1}\left(r_{i, t}\right)=\lambda \operatorname{cov}_{t-1}\left(r_{i, t}, r_{m, t}\right)
$$

where $r_{i, t}$ denotes excess return on the asset $i, r_{m, t}$ excess market return and $\lambda$ the price of risk. In the case of excess market return, (6) becomes:

$$
E_{t-1}\left(r_{m, t}\right)=\lambda \operatorname{var}_{t-1}\left(r_{m, t}\right)
$$

which is estimated with equation

$$
r_{m, t}=\lambda \operatorname{var}_{t-1}\left(r_{m, t}\right)+u_{t}(\text { Model 3) }
$$

This is interpreted as changing risk affecting the stock market return and GARCH-M model is employed to estimate it (for previous applications see Malliaropulos and Priestley 1999; Bekaert and Harvey 1995; Glosten et al. 1993). If the time varying risk is enough to explain the market returns, SAD effects should be irrelevant. This is tested as follows. Residuals $\hat{u}_{t}$ from Equation (8) are regressed on the $S A D_{t}$ and $F_{t}$ variables:

$$
\hat{u}_{t}=\varphi_{0}+\varphi_{1} S A D_{t}+\varphi F_{t}+e_{t}(\text { Model } 4)
$$

and their significance is tested in the model (9). Finally, robustness of $S A D_{t}$ and $F_{t}$ variables will be checked via estimating a GARCH specification of Model (5); comparing the results of estimation of (5) for the return and excess return series; and for the asymmetric effects in variable $F_{t}$ via splitting SAD measure into fall and winter variables and excluding the binary variable $F_{t}$ from the models, as in Kamstra et al. (2003).

\section{Empirical Results}

\subsection{Data Description}

To empirically evaluate SAD effects on the Croatian market, daily data on stock market index CROBEX were collected from Zagreb Stock Exchange (Zagreb Stock Exchange 2021), as well as the interest rate on 91 days Treasury bills from the Ministry of Finance (2021). The total sample consists of 2766 observations, for the period January 4th, 2010 until February 8th, 2021. Returns have been calculated as continuous returns, and excess returns have been calculated by subtracting the daily interest rate on 91-day T-bills (the daily rate was converted from 91-day data via conformal rate). Other variables, such as the SAD variable, were constructed based on the ZSE being in Zagreb. Thus, the latitude of the city Zagreb was utilized in the study, as previous literature usually uses the city in which the stock exchange is placed at) in the models have been constructed based upon the description in the previous section. Descriptive statistics of returns and excess returns are given in Table 2. It can be seen that stylized facts of return series are present in the daily return data, 
which is not surprising at all. The average return over the SAD months was calculated and compared to the rest of the year, in SAD months it is equal to $8.3 \cdot 10^{-5}$, whilst in the other months of the year, it is equal to value -0.0002 . Since a difference exists, formal models and testing could point to the existence of SAD effects on ZSE.

Table 2. Descriptive statistics of CROBEX returns and excess returns.

\begin{tabular}{ccc}
\hline Descriptive Statistics & Return & Excess Return \\
\hline Mean & $-4.37 \times 10^{-5}$ & -0.009 \\
Standard deviation & 0.0075 & 0.0135 \\
Min & -0.1073 & -0.1076 \\
Max & 0.0856 & 0.0626 \\
Skewness & -1.7526 & -1.2474 \\
Kurtosis & 41.477 & 6.498 \\
AR(5) & 94.474 & 69.08 \\
& $(0.000)$ & $(0.000)$ \\
ARCH(5) & 934.32 & 53.09 \\
& $(0.000)$ & $(0.000)$ \\
\hline
\end{tabular}

Note: AR(5) denotes Ljung-Box test of return autocorrelation up to lag 5, ARCH(5) denotes Ljung-Box

test of squared return autocorrelation up to lag $5 ; p$-values are given in parenthesis.

\subsection{Initial Results}

Firstly, we observe only the return series for all of the estimations and in the robustness checking, we observe the excess returns. The basic Model (1) was estimated as a starting point by including the $S A D$ variable. The results are given in Table 3, where other results are sorted by columns (we omit the results of the ARMA part of the return modeling as the control variables, but the full results are available upon request). First of all, the signs of all parameters in all models are in accordance with the theory and previous empirical literature. By observing the column regarding Model (1), it can be seen that the value of the parameter besides this variable is positive and statistically significant. This result is in line with Škrinjarić (2018), in which positive significant SAD effects were found for ZSE in several model specifications. Thus, at a first glance, one could conclude that there is some influence of "winter blues" on the Croatian stock market. In order to test for asymmetric effects, Model (2) was observed by including the Fall variable as well. The value of the parameter $\hat{\beta}_{F}$ is negative, as expected, meaning that investors in Croatia stay away from riskier assets during fall, and revert to them when winter solstice passes. Including the asymmetry variable in the model weakens the effects of the $S A D$ variable. This means that investors' moods are more affected by the changing of the season as winter is coming compared to positive effects after the first day of winter arrives (i.e., negative effects of winter blues are greater compared to recovery after the winter solstice). Thus, it can be concluded that $S A D$ and Fall effects increase the risk aversion of investors on ZSE.

Next, we extend the results in Škrinjarić (2018) to evaluate Models 3 and 4, which have not yet been observed for the Croatian market. In order to test if these effects can be captured in the risk premium via the conditional CAPM, we estimate Models 3 and 4. Basic GARCH(1,1)-M model was sufficient to estimate conditional volatility of excess returns on ZSE (based upon statistical significance of parameters in the model, as well as testing for AR and ARCH effects in residuals). Value of $\hat{\lambda}$ was not found to be significant in the model (meaning that the price of taking a greater risk is not compensated on ZSE). However, we still extract the residuals of Model 3 in order to estimate Model 4. The results are, again, in line with previous literature findings. By allowing the market risk to vary over time, SAD and its asymmetric effects still remain relevant in the residuals. 
Table 3. Estimation results for the $S A D$ and Fall effects.

\begin{tabular}{|c|c|c|c|c|}
\hline Parameter/Diagnostics & Model (1) & Model (2) & Model (3) & Model (4) \\
\hline$\hat{\mu}$ & $9.61 \times 10^{-5}(0.0002)$ & $9.37 \times 10^{-5}(0.0002)$ & - & - \\
\hline$\hat{\beta}_{S A D}$ & $0.0003(0.0001)^{* *}$ & $0.0004(0.0002) * * *$ & - & - \\
\hline$\hat{\beta}_{M O N}$ & $-0.0018(0.0004)^{* * *}$ & $-0.002(0.0004)^{* *}$ & - & - \\
\hline$\hat{\beta}_{\text {Tax }}$ & $0.0017(0.001)$ * & $0.0014(0.0012)$ & & - \\
\hline$\hat{\beta}_{F}$ & & $-0.0003(0.0002) *$ & - & - \\
\hline$\hat{\beta}_{\text {cov }}$ & $-0.0033(0.003)$ & $-0.0035(0.0032)$ & & \\
\hline$\hat{\lambda}$ & - & - & $3.45(3.57)$ & - \\
\hline$\hat{\alpha}_{0, a r c h}$ & - & - & $1.89 \times 10^{-6}\left(3.89 \times 10^{-7}\right)^{* * *}$ & - \\
\hline$\hat{\alpha}_{1, \text { arch }}$ & - & - & $0.096(0.015)^{* * *}$ & - \\
\hline$\hat{\beta}_{1, \text { arch }}$ & - & - & $0.859(0.021)^{* * *}$ & - \\
\hline$\hat{\varphi}_{0}$ & - & - & - & $-0.052(0.025) * *$ \\
\hline$\hat{\varphi}_{1}$ & - & - & - & $0.055(0.019)^{* * *}$ \\
\hline$\hat{\varphi}_{2}$ & - & - & - & $-0.038(0.024)$ * \\
\hline
\end{tabular}

Note: $p$-values are given in parenthesis and are calculated based upon White (1980) heteroskedasticity-consistent t-statistics in models (4), (5) and (9). * ** and ${ }^{* * *}$ denote statistical significance on $10 \%, 5 \%$ and $1 \%$. Ljung-Box test for autocorrelation of residuals was performed in each model and the null of no autocorrelation up to lag 5 could not be rejected for every model on $5 \%$ of significance. Detailed results regarding the diagnostics and goodness of fit are available upon request. This is true for all of the estimated models in the study.

\subsection{Robustness Checking}

The robustness of results was performed by estimating a GARCH specification of the Model 2 via maximum likelihood method (as in Kamstra et al. 2003) of estimation in order to capture the heteroskedasticity of data which was controlled by White (1980) corrections previously (detailed results are available upon request). We estimated a $\mathrm{GARCH}(1,1)$ model with the assumption of skewed GED distribution of errors due to this model specification having the best goodness of fit). The main results are compared in Table 4 , in which the first row shows the original values of parameters besides the $S A D$ and Fall variables and the second row depicts the values in the GARCH model. As it can be seen, the values are very close one to another, even when controlling for the heteroskedasticity of data via a different approach. The values of parameters have the same signs, which is in favor of the robustness of the results.

Table 4. Robustness check of results for Model 2.

\begin{tabular}{ccc}
\hline Parameter/Parameter & $\hat{\beta}_{\text {SAD }}$ & $\hat{\beta}_{F}$ \\
\hline Original (from Table 2) & $0.0004(0.0002)^{* * *}$ & $-0.0003(0.0002)^{*}$ \\
With GARCH specification & $0.0001(0.001)^{* * *}$ & $-0.0002(0.001)^{* *}$ \\
\hline
\end{tabular}

Note $p$-values are given in parenthesis. ${ }^{*}, * *$ and ${ }^{* * *}$ denote statistical significance on $10 \%, 5 \%$ and $1 \%$.

Next, Model 2 was re-estimated for the excess return series (see Table 5), with results compared to the values from Table 3. Again, the values of the estimated parameters are very close one to another and are significant in both cases. This further supports the previous results.

Table 5. Robustness check of results for Model 2, returns vs. excess returns.

\begin{tabular}{ccc}
\hline Parameter/Parameter & $\hat{\beta}_{S A D}$ & $\hat{\beta}_{F}$ \\
\hline Original (from Table 2) & $0.0004(0.0002)^{* * *}$ & $-0.0003(0.0002)^{*}$ \\
With GARCH specification & $0.0002(0.0011)^{* * *}$ & $-0.0002(0.019)^{* *}$ \\
\hline
\end{tabular}

Note $p$-values are given in parenthesis. ${ }^{*}{ }^{* *}$ and ${ }^{* * *}$ denote statistical significance on $10 \%, 5 \%$ and $1 \%$.

Finally, the robustness of measure Fall was observed by dividing it into two variables: $\mathrm{SAD}$ only for fall and SAD only for winter, $S A D_{f}$ and $S A D_{w}$, respectively. Results are shown in Table 6, where it can be seen that the differences between fall and winter SAD effects are equal to differences in the original specification in the model (from Table 3). 
Moreover, SAD effects are stronger in the wintertime, as it was found in the original model in Table 3. Thus, we find the results to fairly be robust and useful in future research.

Table 6. Robustness check of results for Fall variable.

\begin{tabular}{|c|c|c|c|c|}
\hline \multirow{2}{*}{$\begin{array}{l}\text { Parameter/ } \\
\text { Diagnostics }\end{array}$} & \multicolumn{2}{|c|}{ Model 2} & \multicolumn{2}{|c|}{ Model 4} \\
\hline & $\operatorname{SAD} f$ and $w$ & $\begin{array}{l}\text { Relation to the } \\
\text { Original Model }\end{array}$ & SAD $f$ and $w$ & $\begin{array}{c}\text { Relation to the Original } \\
\text { Model }\end{array}$ \\
\hline$\hat{\beta}_{f}$ & $0.0002(0.520)$ & Difference between & - & - \\
\hline$\hat{\beta}_{w}$ & $0.0004(0.0002) * * *$ & estimated values as for & - & - \\
\hline$\hat{\varphi}_{f}$ & - & $\hat{\beta}_{S A D}$ and $\hat{\beta}_{F}$ & $0.0001(0.631)$ & Difference between estimated \\
\hline$\hat{\varphi}_{w}$ & - & & $0.0005(0.000)^{* * *}$ & values as for $\hat{\varphi}_{1}$ and $\hat{\varphi}_{2}$ \\
\hline
\end{tabular}

Note: $p$-values are given in parenthesis and are calculated based upon White (1980) heteroskedasticity-consistent $t$-statistics in Models 1,2 and 4 .** denote statistical significance on 1\%. In order to estimate Models 2 and 4 with two variables of Fall, the following specifications of Models 2 and 4 are considered: $r_{t}=\mu+f(A R M A)+\beta_{M} M O N_{t}+\beta_{\operatorname{Tax}} \operatorname{Tax}_{t}+\beta_{f} S A D_{f, t}+\beta_{w} S A D_{w, t}+\beta_{\mathrm{cov}} \operatorname{Cov}_{t}+\varepsilon_{t}$ and $\hat{u}_{t}=\varphi_{0}+\varphi_{f} S A D_{f, t}+\varphi_{w} S A D_{w, t}+e_{t}$.

\subsection{Simple Investing Strategies Simulation}

Finally, as a simple exercise, three variations of trading strategies which are based on the aforementioned results were simulated. In that way, the portfolio values can be compared to a benchmark one, the buy and hold portfolio. Figure 1 depicts the portfolio values, in which it is assumed the following:

(i) First strategy is the SAD_W, in which the investor uses the contrarian strategy where he buys the stock market index before the winter time and holds it during the winter. When spring comes, he sells the index and holds the money until the new winter season arrives.

(ii) Second strategy is SAD_W+F, in which investor uses contrarian strategy again (as previous one), but adds the information about asymmetric effect of the fall time. Thus, when the variable Fall is not equal to zero, then the investor does not sell the index, as returns fall additionally. Opposite is true for Fall being equal to zero.

(iii) Third strategy is SAD_F, in which the investor uses the contrarian strategy, in which he buys the index when the value of Fall is not equal to zero due to lower returns, and holds the index until it is ready to be sold (when the value of Fall is zero).

(iv) Fourth strategy is simulated based on those investors who are affected by the SAD effects and do the wrong thing, sell when the returns are expected to rise, and buy when the returns are expected to fall. This is called "affected".

All five strategies are shown in Figure 1. The benchmark is better than the "affected" portfolio. However, the strategies in which the investor aims to capitalize on the results obtained in this research provide him with overall good portfolio values. As all strategies started with one unit value at the starting date, the changes of portfolio values indicate that the investor could have obtain good returns by exploiting the knowledge about the $S A D_{w}$ variable and its effects on the return series. The COVID-19 crisis has been ignored, although strategies could have included the contrarian approach here as well. This means that those who aim to exploit inefficiencies such as the SAD effects could have exploited the effects of the pandemic on stock markets. Previous literature (Zhang et al. 2020; Barro et al. 2020; He et al. 2020) has indicated that short-term effects in return series existed. This means that the strategies aiming in exploiting all these predictable issues could have performed even better. This preliminary analysis could be a basis for more sophisticated trading strategies which could be observed in future work. 


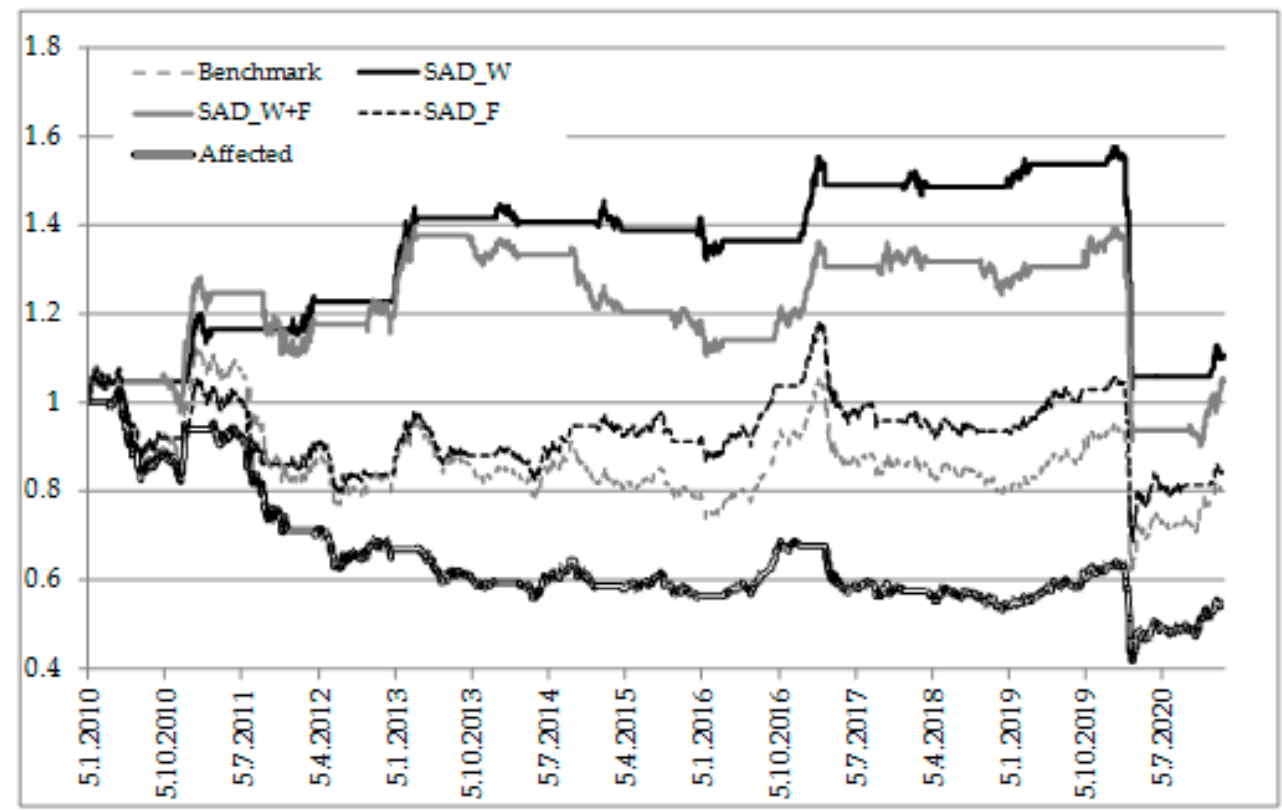

Figure 1. Values of simulated portfolio values.

\subsection{Discussion}

The results of this research are in line with previous literature (both cited in the literature review section), but in line with other research regarding market inefficiencies. Namely, Stoica and Diaconasu (2011) found that the Croatian stock market is one of the most inclined in violating the EHM in its weak form. Similar findings are in Ferreira (2018), where the author performed dynamic analysis of 18 Eastern European markets (including Croatian one). Here, the detrended fluctuation analysis shows that majority of analyzed markets are distant from the absence of long-range dependencies. This is usually interpreted as inefficiency. However, the author is cautious if this could be exploited due to illiquidity in the majority of these markets. Dragotă and Ţilică (2014) found results in favor of EHM for Croatia, but this is contrary not only to the findings here but to the Heininen and Puttonen (2008); Gakhovich (2011), aforementioned Stoica and Diaconasu (2011) and Smith (2012). If we reflect on the theoretical models, Mehra and Sah (2002) explain the theory of projection bias and moods. In this theory, the individual makes decisions today, with the assumption that the circumstances today will not change in the future. However, when time passes, preferences change over time and people do not account for those changing preferences. As a result, the authors conclude that small changes in the individual investor's discount factors result in large changes in equity prices.

Next, by comparing the results found here to previous EMH literature regarding the Croatian market; it is found that Barbić (2010) results confirmed that the weak form of EMH is violated on ZSE, but the author questions if the results would be exploitable when transaction costs are taken into consideration. Similar results and conclusions are found in Šonje et al. (2011). Maria et al. (2013) observed selected CESEE markets and their long-term memories. The Croatian was found to be inefficient within the methodology used in the paper. Some newer results regarding Croatia are the following: Stoitsova-Stoykova (2017) augmented the asymmetric GARCH models on selected stock markets with the Phillips curve regarding inflation expectations. However, the results still indicated that ZSE is violating the weak form of EMH. As trading costs usually make problems within testing the possibility of exploiting some anomaly, future research needs to focus on this aspect more, e.g., Škrinjarić (2020) has focused on particular stocks on ZSE, and although the transaction costs were included (and varied in the analysis), the trading strategies observed in this study still beat the market and other investment strategies. Although this research is not directly comparable to the research we are conducting here, the author focuses on the 
same market and finds within investor's utility theory that certain gains could be achieved on this market.

\section{Conclusions}

If found on stock markets, seasonal affective disorder effects could potentially have several consequences: both in theory and practice. This is referring to the EMH and potential distorted assumptions and conclusions within rational models, as well as trying to make extra profits due to market inefficiencies. However, as always, the results of each research should be interpreted with caution. Firstly, there will always be those who defend one school of thought or the other. This is natural in human behavior. Secondly, the "old" models which are mostly based on rational investor assumptions were being used extensively over the decades, as they were easier to manipulate in mathematical terms. Nowadays, new technology and the construction of specific variables have contributed to the development of newer approaches in theory and modeling. That is why Ying et al. (2019) explain that finding any type of anomalies compared to the established paradigms does not mean that they are wrong. On the other side, if some findings are persistent over time, such as this research, we cannot always refer to them as data snooping. As Grable and Roszkowski (2008) state, if such findings (the relationship between investor mood and risk tolerance) are significant, these insights should be incorporated into economic utility theories. Our findings suggest that risk aversion is changing depending on the time of the year.

This research observed SAD effects on the Croatian market. Main findings indicate that SAD affects investors which trade on the Croatian market. The returns are greater in fall time compared to the winter time after the winter solstice. This means that investor mood changes. The depressive behavior caused by the shortening of day hours leads to selling riskier assets in fall. This has the consequence of making price pressures. The other consequence of the SAD effect is buying more risky stocks when day hours start to get longer. This decreases market returns. These findings are in accordance with theory and previous empirical research, meaning that investors on ZSE are characterized with varying risk aversion over the year, which leads to different patterns in stock returns, as well in their portfolio holdings. Such results are meaningful in several ways. Firstly, contrarian investment strategies on ZSE could be constructed in order to benefit from such behavior. If this behavior is persistent over time, maybe it could be exploited (in a better way compared to our simple strategies). We leave this question for future research. Secondly, consequences exist in employing asset pricing models that assume rational behavior and constant risk aversion over time. This is true at least for markets similar to the one observed in this study. Since some evidence exists on time-varying risk aversion due to mood changes over the seasons, this should be taken into consideration when empirically evaluating asset pricing models on ZSE. Finally, the robustness of results was performed in several ways. In the original model, we include several control variables in order to avoid spurious results. Thus, SAD effects exist even when controlling for Monday, tax, COVID-19 and autocorrelation effects in market returns, as well as by checking with different specifications of the same model.

There were several limitations and shortfalls of this research. Firstly, we focused on one stock market and its characteristics. International investors are aiming for diversification. Thus, future work should explore these issues simultaneously on several markets. This could enable a detailed analysis of trading possibilities within the international portfolio context. Next, we focused on the stock market. However, other financial assets could have been affected, due to investors including other assets in their portfolios as well. This also has potential for future exploration of potential gains in financial markets. Next, the estimation procedure was based on the whole sample observed at once, i.e., the estimated parameters are assumed to be constant over time. The SAD effects on the return and risk series could be changing over time, due to various reasons. This could be explored in the future as well. This could especially be true with new problems regarding the overall 
sentiment of the population in pandemic times and global lockdowns. The general picture was observed in terms of the total market index. However, a sectoral analysis could have pointed out different scenarios of return and risk reactions. This is also left for future research to examine.

Future work will include exploring SAD effects in more detail on regional markets as well, in order to get insights into the situation on CEE and SEE markets as well. This would provide better information about the movements on these markets, so that interested investors could make easier decisions about (non) investing. Moreover, the robustness of results will be checked even further, by including other possible control variables in the model, such as interest or exchange rates. As the SAD effects could be found in these series as well, a detailed examination is needed so that possible trading strategies could be considered for exploiting such information. Since this is one of the first studies of this kind in Croatia, and CEE markets as well, there is hope to further develop this research in the future. Since we have simulated simple trading strategies based on the obtained results, future work is going to focus on investment strategies which will include the knowledge about the SAD effects on return and risk series, as well as more markets at once so that international diversification possibilities will be observed.

Author Contributions: All authors have contributed to all of the parts of the paper equally. All authors have read and agreed to the published version of the manuscript.

Funding: This research received no external funding.

Institutional Review Board Statement: Not applicable.

Informed Consent Statement: Not applicable.

Data Availability Statement: Publicly available datasets were analyzed in this study. The data can be found here: http:/ / www.zse.hr, http:/ / www.investing.com.

Acknowledgments: Authors are grateful to the reviewers for their useful comments.

Conflicts of Interest: The authors declare no conflict of interest. The funders had no role in the design of the study; in the collection, analyses, or interpretation of data; in the writing of the manuscript, or in the decision to publish the results.

\section{References}

Agrawal, Anup, and Kishore Tandon. 1994. Anomalies or illusions? Evidence from stock markets in eighteen countries. Journal of International Money and Finance 13: 83-106. [CrossRef]

Baele, Lieven, Geert Bekaert, and Larissa Schäfer. 2015. An Anatomy of Central and Eastern European Equity Markets. Columbia Business School Working Paper, No. 15-71. Singapore: Columbia Business School.

Baker, Malcom, and Jeffery Wurgler. 2006. Investor sentiment and the cross-section of stock returns. The Journal of Finance 61: 1645-80. [CrossRef]

Baker, Malcom, and Jeffery Wurgler. 2007. Investor sentiment in the stock market. Journal of Economic Perspectives 21: 129-52. [CrossRef]

Balcilar, Mehmet, Rangan Gupta, and Clement Kyei. 2018. Predicting stock returns and volatility with investor sentiment indices: A reconsideration using a nonparametric causality in quantiles test. Bulletin of Economic Research 70: 74-87. [CrossRef]

Banchit, Azilawati, Sazali Abidin, Sophyafadeth Lim, and Fareiny Morni. 2020. Investor Sentiment, Portfolio Returns, and Macroeconomic Variables. Journal of Risk and Financial Management 13: 259. [CrossRef]

Barbić, Tajana. 2010. Testiranje slabog oblika hipoteze efikasnog tržišta na hrvatskom tržištu dionica (Testing the weak form of efficient market hypothesis on Croatian stock market). Proceedings of the Faculty of Economics and Business in Zagreb. Zbornik Ekonomskog fakulteta u Zagrebu 8: 155-72.

Barro, Robert Joseph, Jose Ursua, and Joanna Weng. 2020. The coronavirus and the great influenza pandemic: Lessons from the "Spanish Flu" for the coronavirus's potential effects on mortality and economic activity. National Bureau Economic Research, w26866. [CrossRef]

Bathia, Deven, and Don Bredin. 2013. An examination of investor sentiment effect on G7 stock market returns. The European Journal of Finance 19: 909-37. [CrossRef]

Bekaert, Geert, and Campbell Harvey. 1995. Time-varying world market integration. Journal of Finance 50: 403-44. [CrossRef]

Cao, Melanie, and Jason Wei. 2005. Stock market returns: A note on temperature anomaly. Journal of Banking E Finance $296: 1559-73$.

Concetto, Chiara Limongi, and Francesco Ravazzolo. 2019. Optimism in Financial Markets: Stock Market Returns and Investor Sentiments. Journal of Risk and Financial Management 12: 1-14. 
De Long, Bradford, Andrei Shleifer, Lawrence Summers, and Robert Waldmann. 1990. Noise trader risk in financial markets. Journal of Political Economy 98: 703-38. [CrossRef]

Denissen, Jaap, Ligaya Butalid, Lars Penke, and Marcel van Aken. 2008. The effects of weather on daily mood: A multilevel approach. Emotion 85: 662-67. [CrossRef] [PubMed]

Dolvin, Steven, and Mark Pyles. 2007. Seasonal affective disorder and the pricing of IPOs. Review of Accounting and Finance 62: 214-28. [CrossRef]

Dolvin, Steven, Mark Pyles, and Q. Wu. 2009. Analysts Get SAD Too: The Effect of Seasonal Affective Disorder on Stock Analysts' Earnings. The Journal of Behavioral Finance 10: 214-25. [CrossRef]

Dowling, Michael, and Brian M. Lucey. 2005. Weather, Biorhythms, Beliefs and Stock Returns—Some Preliminary Irish Evidence. International Review of Financial Analysis 143: 337-55. [CrossRef]

Dowling, Michael, and Brian Lucey. 2008. Robust Global Mood Influences in Equity Pricing. Journal of Multinational Financial Management 182: 145-64. [CrossRef]

Dragotă, Victor, and Elena Ţilică. 2014. Market efficiency of the Post Communist East European stock markets. Central European Journal of Operations Research 22: 307-37. [CrossRef]

Du, Ding, Ronald Gunderson, and Xiaobing Zhao. 2016. Investor sentiment and oil prices. Journal of Asset Management 17: 73-88. [CrossRef]

Fama, Eugene Francis. 1965. The Behavior of Stock-Market Prices. Journal of Business 64: 34-105. [CrossRef]

Fama, Eugene Francis. 1970. Efficient Capital Markets: A Review of Theory and Empirical Work. The Journal of Finance 252: $383-417$. [CrossRef]

Ferreira, Paulo. 2018. Long-range dependencies of Eastern European stock markets: A dynamic detrended analysis. Physica A 505: 454-70. [CrossRef]

Forgas, Joseph. 1995. Mood and judgment: The affect infusion model (AIM). Psychological Bulletin 117: 39-66. [CrossRef] [PubMed]

Gakhovich, Alexander. 2011. The Holiday Effect in the Central and Eastern European Financial Markets. Dissertation, Auckland University of Technology, Auckland, New Zealand.

Garrett, Ian, Mark Kamstra, and Lisa Kramer. 2005. Winter Blues and Time Variation in the Price of Risk. Journal of Empirical Finance 12: 291-316. [CrossRef]

Glosten, Lawrence, Ravi Jagannathan, and David Runkle. 1993. On the relation between the expected value and the volatility of the nominal excess returns on stocks. The Journal of Finance 48: 1779-801. [CrossRef]

Golab, Anna, David Allen, and Robert Powell. 2015. Aspects of Volatility and Correlations in European Emerging Economies. In Emerging Markets and Sovereign Risk. Edited by Finch Nigel. London: Palgrave Macmillan.

Grable, John, and Michael Roszkowski. 2008. The influence of mood on the willingness to take financial risks. Journal of Risk Research 11: 905-23. [CrossRef]

Hammami, Fatma, and Ezzeddine Abaoub. 2011. Winter Blues, Investor Mood and Stock Market Returns: Evidence from the Tunisian Stock Exchange. Journal of Applied Finance 172: 46-58.

He, Pinglin, Yulong Sun, Ying Zhang, and Tao Li. 2020. COVID-19's Impact on Stock Prices Across Different Sectors-An Event Study Based on the Chinese Stock Market. Emerging Markets Finance and Trade 56: 2198-212. [CrossRef]

Heininen, Polina, and Vesa Puttonen. 2008. Stock Market Efficiency in the Transition Economies through the Lens of Calendar Anomalies. Paper presented at the 10th Biannual EACES Conference, Moscow, Russia, August 28.

Hirshleifer, David, and Tyler Shumway. 2003. Good day sunshine: Stock returns and the weather. The Journal of Finance 583: 1009-32. [CrossRef]

Huang, Dashan, Fuwei Jiang, Jun Tu, and Goufu Zhou. 2014. Investor sentiment aligned: A powerful predictor of stock returns. Review of Financial Studies 28: 791-37. [CrossRef]

Isen, Alice, and Robert Patrick. 1983. The effect of positive feelings on risk taking: When the chips are down. Organizational Behavior and Human Performance 31: 194-202. [CrossRef]

Isen, Alice, Thomas Nygren, and Gregory Ashby. 1988. Influence of positive affect on the subjective utility of gains and losses: It is just not worth the risk. Journal of Personality and Social Psychology 55: 710-17. [CrossRef]

Jacobsen, Ben, and Wessel Marquering. 2008. Is it the weather? Journal of Banking E Finance 324: 526-40.

Johnson, Eric, and Amos Tversky. 1983. Affect, generalization, and the perception of risk. Journal of Personality and Social Psychology 451: 20-31. [CrossRef]

Kahneman, Daniel, and Amos Tversky. 1979. Prospect Theory: An Analysis of Decision Under Risk. Econometrica 472: $263-91$. [CrossRef]

Kamstra, Mark, Lisa Kramer, and Maurice Levi. 2002. Losing Sleep at the Market. American Economic Review 924: 1251-56.

Kamstra, Mark, Lisa Kramer, and Maurice Levi. 2003. Winter Blues: A SAD Stock Market Cycle. American Economic Review 931: 324-43. [CrossRef]

Kamstra, Mark, Lisa Kramer, and Maurice Levi. 2008a. Opposing Seasonalities in Treasury Versus Equity Returns. Working paper. Toronto: University of Toronto.

Kamstra, Mark, Lisa Kramer, Maurice Levi, and Wermers Russ. 2008b. Seasonal Asset Allocation: Evidence from Mutual Fund Flows. Working paper. Toronto: University of Toronto.

Kamstra, Mark, Lisa Kramer, and Maurice Levi. 2009. Is it the weather? Comment. Journal of Banking E Finance 333: 578-82. 
Kliger, Doron, and Ori Levy. 2008. Mood Impacts on Probability Weighting Funcitons: Large-Gamble Evidence. Journal of SocioEconomics 374: 1397-411. [CrossRef]

Kramer, Lisa, and Mark Weber. 2011. This is Your Portfolio on Winter: Seasonal Affective Disorder and Risk Aversion in Financial Decision Making. Social Psychological and Personality Science 3: 193-99. [CrossRef]

Kyriazis, Nikolaos. 2019. A Survey on Efficiency and Profitable Trading Opportunities in Cryptocurrency Markets. Journal of Risk and Financial Management 12: 67. [CrossRef]

Laeven, Luc, and Fabian Valencia. 2008. Systemic Banking Crises: A New Database. IMF Working Paper WP/08/224. Washington, DC: IMF.

Lakonishok, Josef, and Seymour Smidt. 1988. Are seasonal anomalies real? A ninety year perspective. Review of Financial Studies 1: 403-25. [CrossRef]

Lee, Wayne, Christine Jiang, and Daniel Indro. 2002. Stock market volatility, excess returns, and the role of investor sentiment. Journal of Banking E Finance 26: 2277-99.

Lo, Kin, and Serena Wu. 2018. The Impact of Seasonal Affective Disorder on Financial Analysts. The Accounting Review 93: 309-33. [CrossRef]

Loewenstein, George, Elke Weber, Christopher Hsee, and Ned Welch. 2001. Risk as feelings. Psychological Bulletin 1272: 267-86. [CrossRef]

Malliaropulos, Dimitrios, and Richard Priestley. 1999. Mean reversion in Southeast Asian stock markets. Journal of Empirical Finance 6 : 355-84. [CrossRef]

Maria, Pece Andrea, Ludisan Emilia Anuta, and Mutu Simona. 2013. Testing the long range-dependence for the Central Eastern European and the Balkans stock markets. Annals of the University of Oradea, Economic Science Series 22: 1113-24.

Mayoclinic. 2018. Available online: https://www.mayoclinic.org/diseases-conditions/seasonal-affective-disorder/symptoms-causes/ syc-20364651 (accessed on 13 July 2018).

Mehra, Rajnish, and Raaj Sah. 2002. Mood fluctuations, projection bias, and volatility of equity prices. Journal of Economic Dynamics and Control 26: 869-87. [CrossRef]

Merton, Robert. 1973. An Intertemporal Capital Asset Pricing Model. Econometrica 415: 867-87. [CrossRef]

Miller, Edward. 1988. Why a weekend effect. The Journal of Portfolio Management 14: 43-48. [CrossRef]

Milošević Avdalović, Snežana, and Ivan Milenković. 2017. January effect on stock returns: Evidence from emerging Balkan equity markets. Industrija 45: 7-21. [CrossRef]

Ministry of Finance. 2021. Available online: http:/ / www.mfin.hr (accessed on 14 July 2018).

Muller, Luisa, Dirk Schiereck, Marc Simpson, and Christian Voigt. 2009. Daylight saving effect. Journal of Multinational Financial Management 192: 127-38. [CrossRef]

Murgea, Aurora. 2016. Seasonal affective disorder and the Romanian stock market. Economic Research-Ekonomska Istraživanja 291: 177-92. [CrossRef]

Naik, Pramod Kumar, and Puja Padhi. 2016. Investor sentiment, stock market returns and volatility: Evidence from National Stock Exchange of India. International Journal of Management Practice 9: 213-37. [CrossRef]

Pinegar, Michael. 2002. Losing sleep at the market: Comment. American Economic Review 92: 1251-56. [CrossRef]

Radovanov, Boris, and Aleksandra Marcikić. 2017. Bootstrap testing of trading strategies in emerging Balkan stock markets. EEM Economics and Management 20: 103-19.

Roecklein, Kathyrin, and Kelly Rohan. 2005. Seasonal Affective Disorder An overview and Update. Psychiatry 2005: $20-26$.

Rosenthal, Norman. 1998. Winter Blues: Seasonal Affective Disorder-What It Is and How to Overcome It. New York: The Guilford Press.

Rosenthal, Norman. 2012. Winter Blues: Everything You Need to Know to Beat Seasonal Affective Disorder. New York: The Guilford Press.

Rosenthal, Norman, David Sack, Christiansan Gillin, Alfred Lewy, Frederick Goodwin, Yolande Davenport, Peter Mueller, David Newsome, and Thomas Wehr. 1984. Seasonal affective disorder. A description of the syndrome and preliminary findings with light therapy. Archives of General Psychiatry 41: 72-80. [CrossRef] [PubMed]

Rupande, Lorriane, Hilary Tinotenda Muguto, and Paul-Francois Muzindutsi. 2019. Investor sentiment and stock return volatility: Evidence from the Johannesburg stock exchange. Cogent Economics and Finance 7: 1600233. [CrossRef]

Saunders, Edward. 1993. Stock prices and Wall Street weather. American Economic Review 835: 1337-45.

Šego, Boško, and Tihana Škrinjarić. 2018. Quantitative research of Zagreb stock exchange-literature overview for the period from establishment until 2018. Economic Review (Ekonomski Pregled) 69: 655-734.

Shleifer, Andrei. 1999. Inefficient Markets: An Introduction to Behavioral Finance. New York: Oxford University Press.

Škrinjarić, Tihana. 2012. The calendar effects on stock returns Kalendarski učinci u prinosima dionica. Economic Review (Ekonomski Pregled) 63: 651-78.

Škrinjarić, Tihana. 2018. Testing for Seasonal Affective Disorder on selected CEE and SEE stock markets. Risks 6: 140. [CrossRef]

Škrinjarić, Tihana. 2020. Dynamic portfolio optimization based on grey relational analysis approach. Expert Systems with Applications 147: 113207. [CrossRef]

Škrinjarić, Tihana, and Zrinka Orlović. 2020. Economic policy uncertainty and stock market spillovers: Case of selected CEE markets. Mathematics 8: 1077. [CrossRef]

Škrinjarić, Tihana, Zrinka Lovretin Golubić, and Zrinka Orlović. 2020. Empirical analysis of dynamic spillovers between exchange rate return, return volatility and investor sentiment. Studies in Economics and Finance 2020: 1-28. 
Smith, Graham. 2012. The changing and relative efficiency of European emerging stock markets. European Journal of Finance 18: 689-708. [CrossRef]

Šonje, Velimir, Denis Alajbeg, and Zoran Bubaš. 2011. Efficient market hypothesis: Is the Croatian stock market as (in)efficient as the U.S. market. Financial Theory and Practice 35: 301-26. [CrossRef]

Stefanescu, Razvan, and Ramona Dumitriu. 2011. The SAD Cycle for the Bucharest Stock Exchange. MPRA Working paper No. 41889. Munich: University Library of Munich.

Stoica, Ovidiu, and Delia-Elena Diaconasu. 2011. An Examination of the Calendar Anomalies on Emerging Central and Eastern European Stock Markets. Recent Researchers in Applied Economics. Conference Paper: 3rd World Multiconference on Applied Economics, Business and Development. Available online: http://www.wseas.us/e-library/conferences/2011/Iasi/AEBD/ AEBD-19.pdf (accessed on 10 February 2021).

Stoitsova-Stoykova, Ani. 2017. Relationship Between Public Expectations and Financial Market Dynamics in South-East Europe Capital Markets. Economic Alternatives 2: 237-50.

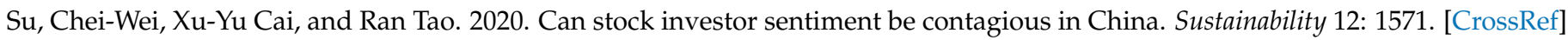

White, Hulbert. 1980. A heteroskedasticity-consistent covariance matrix estimator and direct test for heteroskedasticity. Econometrica 48: 817-38. [CrossRef]

Xu, Cheng. 2016. Are UK Financial Markets SAD? A Behavioural Finance Analysis. Ph.D. thesis, University of Sheffield, Sheffield, UK.

Ying, Quianwei, Tahir Yousaf, Qurat ul Ain, Yasmeen Akhtar, and Muhammad Shahid Rasheed. 2019. Stock Investment and Excess Returns: A Critical Review in the Light of the Efficient Market Hypothesis. Journal of Risk and Financial Management 12 : 97. [CrossRef]

Yu, Hai-Chin Yu, Michael S. Pagano, and Chia-Yi Wu. 2011. Intraday Returns and Weekday Effects in the Dow Jones and Nasdaq Stock Indexes. International Research Journal of Finance and Economics 68: 14-34.

Zhang, Dayong, Min Hu, and Qiang Ji. 2020. Financial Markets Under the Global Pandemic of COVID-19. Finance Research Letters. Forthcoming. [CrossRef] [PubMed]

Zagreb Stock Exchange. 2021. Available online: http:/ / www.zse.hr (accessed on 10 February 2021). 